Research article

\title{
Generation and analysis of ESTs from the eastern oyster, Crassostrea virginica Gmelin and identification of microsatellite and SNP markers
}

\author{
Jonas Quilang1,2, Shaolin Wang ${ }^{1}$, Ping Li ${ }^{1}$, Jason Abernathy ${ }^{1}$, Eric Peatman ${ }^{1}$, \\ Yongping Wang ${ }^{3}$, Lingling Wang ${ }^{3}$, Yaohua Shi ${ }^{3}$, Richard Wallace ${ }^{1}$, \\ Ximing $\mathrm{Guo}^{3}$ and Zhanjiang Liu*1
}

\begin{abstract}
Address: ${ }^{1}$ The Fish Molecular Genetics and Biotechnology Laboratory, Department of Fisheries and Allied Aquacultures and Program of Cell and Molecular Biosciences, Aquatic Genomics Unit, 203 Swingle Hall, Auburn University, Auburn, AL 36849, USA, ${ }^{2}$ Institute of Biology, College of Science, University of the Philippines, 1101 Diliman, Quezon City, Philippines and ${ }^{3}$ Haskin Shellfish Research Laboratory, Institute of Marine and Coastal Sciences, Rutgers University, 6959 Miller Ave., Port Norris, NJ 08349, USA

Email: Jonas Quilang - jpquilang@gmail.com; Shaolin Wang - wangsha@auburn.edu; Ping Li - lping1@auburn.edu; Jason Abernathy - abernjw@auburn.edu; Eric Peatman - epeatman@gmail.com; Yongping Wang - wyongping@yahoo.com Lingling Wang - lingling@hsrl.rutgers.edu; Yaohua Shi - yaohua@hsrl.rutgers.edu; Richard Wallace - rwallace@auburn.edu; Ximing Guo - xguo@ hsrl.rutgers.edu; Zhanjiang Liu* - liuzhan@auburn.edu

* Corresponding author
\end{abstract}

Published: 8 June 2007

BMC Genomics 2007, 8:157 doi:10.1/86/147|-2164-8-157

This article is available from: http://www.biomedcentral.com/I47I-2/64/8/I57

(c) 2007 Quilang et al; licensee BioMed Central Ltd.

This is an Open Access article distributed under the terms of the Creative Commons Attribution License (http://creativecommons.org/licenses/by/2.0), which permits unrestricted use, distribution, and reproduction in any medium, provided the original work is properly cited.

\begin{abstract}
Background: The eastern oyster, Crassostrea virginica (Gmelin 1791), is an economically important species cultured in many areas in North America. It is also ecologically important because of the impact of its filter feeding behaviour on water quality. Populations of $C$. virginica have been threatened by overfishing, habitat degradation, and diseases. Through genome research, strategies are being developed to reverse its population decline. However, large-scale expressed sequence tag (EST) resources have been lacking for this species. Efficient generation of EST resources from this species has been hindered by a high redundancy of transcripts. The objectives of this study were to construct a normalized cDNA library for efficient EST analysis, to generate thousands of ESTs, and to analyze the ESTs for microsatellites and potential single nucleotide polymorphisms (SNPs).

Results: A normalized and subtracted $C$. virginica cDNA library was constructed from pooled RNA isolated from hemocytes, mantle, gill, gonad and digestive tract, muscle, and a whole juvenile oyster. A total of 6,528 clones were sequenced from this library generating 5,542 high-quality EST sequences. Cluster analysis indicated the presence of 635 contigs and 4,053 singletons, generating a total of 4,688 unique sequences. About $46 \%(2,174)$ of the unique ESTs had significant hits (E-value $\leq \mathrm{Ie}-05)$ to the non-redundant protein database; I, 104 of which were annotated using Gene Ontology (GO) terms. A total of 35 microsatellites were identified from the ESTs, with 18 having sufficient flanking sequences for primer design. A total of 6,533 putative SNPs were also identified using all existing and the newly generated EST resources of the eastern oysters.
\end{abstract}

Conclusion: A high quality normalized cDNA library was constructed. A total of 5,542 ESTs were generated representing 4,688 unique sequences. Putative microsatellite and SNP markers were identified. These genome resources provide the material basis for future microarray development, marker validation, and genetic linkage and QTL analysis. 


\section{Background}

The eastern oyster, Crassostrea virginica (Gmelin, 1791) occurs naturally in the Western Atlantic from the Gulf of St. Lawrence in Canada to the Gulf of Mexico, Caribbean, and coasts of Brazil and Argentina [1]. This species has been introduced to the Pacific coast of North America, Europe, and Hawaii but it has maintained reproducing populations in only two localities outside its natural range, namely, in a river in British Columbia and in a small basin in Hawaii [2]. It thrives in estuaries and coastal areas and is present in some areas as extensive reefs. These reefs are vital components of estuarine ecosystems because they not only serve as habitat for many fishes but also as a refuge for them and for some reef-associated invertebrates when environmental conditions become stressful [3]. The eastern oyster is an economically important species in North America as natural populations are being harvested extensively. It is also being cultivated in many areas. The eastern oyster populations have been threatened by overfishing and habitat degradation as a result of expanding utilization of coastlines and other anthropogenic disturbances $[3,4]$. Outbreak of major diseases such as Dermo (caused by a protozoan pathogen, Perkinsus marinus) and MSX (Multinucleate Sphere X, caused by another protozoan Haplosporidium nelsoni) have devastated both farmed and wild populations of the oyster species.

Oysters are a fundamental component of the aquatic ecosystem in addition to their importance to fisheries and aquaculture industries. As filter-feeding bivalves, oysters play a critical role in maintaining water quality [5]. The eastern oyster has also been used as a marine bivalve model to study the effects of environmental stressors [6] and as bioindicators of estuarine pollution [7,8]. A number of genome resources have been developed from the eastern oyster including construction of a framework genetic linkage map [9], construction of large-insert BAC libraries [10], initial analysis of expressed sequence tags (EST) [11-13], and construction of the first generation microarray [14].

EST analysis is not only the most efficient approach for gene discovery, but also an effective approach for the identification of polymorphic DNA markers such as microsatellites and single nucleotide polymorphisms $[15,16]$ that are highly useful for genetic mapping and comparative genome analysis. However, EST analysis in the eastern oysters has been hindered by highly abundantly expressed genes in oysters including a very high proportion of mitochondrial genes $[12,17]$. Compared to the very large efforts for the development of EST resources for the Pacific oysters $([18,19]$, and the ongoing efforts at the Joint Genome Institute), the EST resource in the eastern oyster is small. To date, only 9,018 ESTs have been deposited to
GenBank from C. virginica. Due to high redundancy rate of the oyster ESTs, the unique genes represented by these ESTs are relatively small. The objectives of this study were to construct a normalized cDNA library for efficient generation of unique ESTs from the eastern oysters, and to generate additional ESTs from the normalized cDNA library. Here we report the construction of a high-quality normalized cDNA library and the generation and analysis of 5,542 ESTs.

The number of microsatellite markers available for mapping has been low. To date, there are about 104 microsatellite markers developed from the eastern oyster. Seven (7) polymorphic microsatellite markers were developed from a size-selected (400 - $900 \mathrm{bp}$ ) partial genome library [20]. Eighteen (18) microsatellite markers were developed by screening 743 clone sequences for microsatellite repeats from a small-insert $C$. virginica genomic library [21]. Sixty one (61) EST-linked microsatellite markers were developed by screening eastern oyster sequences from public databases $[22,23]$. Three (3) microsatellites were isolated from C. virginica genomic DNA [24]. Eleven (11) microsatellites were originally developed from $C$. gigas which also yielded cross-species amplifications in $C$. virginica $[25,26]$. The remaining four microsatellite markers were developed by the Haskin Shellfish Research laboratory at Rutgers University, USA [27]. In this work, we have identified 35 microsatellites within the sequenced ESTs, of which 18 have sufficient flanking sequences for primer design. Using the sequenced ESTs, along with those ESTs already existing in the GenBank, we identified 6,533 single nucleotide polymorphic sites that are potentially useful for genetic linkage mapping and QTL analysis in this species.

\section{Results \\ Generation of ESTs and contig assembly}

A total of 6,528 randomly picked EST clones were sequenced, producing 6,349 readable sequences (97.3\% sequencing success rate). After removal of clones with no inserts or very short inserts (100 bp cutoff), a total of 5,542 high-quality ESTs (Table 1 ) were produced with an average length of $473 \mathrm{bp}$. The cumulative length of all high-quality EST sequences was 2,622,701 bases. All the ESTs have been deposited to GenBank with continuous accession numbers of EH643873 - EH649414.

The ESTs were subjected to cluster analysis using three software, PHRAP, CAP3, and Vector NTI Advance ${ }^{\mathrm{TM}} 10$, with the final contigs assembled with Vector NTI Advance ${ }^{\mathrm{TM}} 10$. A total of 635 contigs were assembled consisting of 1,489 ESTs while 4,053 sequences were singletons (Table 1). Thus, this EST project allowed identification of 4,688 unique sequences. Of the 635 contigs, 500 contained 2 ESTs $(78.7 \%) ; 108$ contained 3 ESTs 
Table I: Summary Statistics of ESTs generated from the eastern oyster, $C$. virginica

\begin{tabular}{lc}
\hline Feature & Value \\
\hline Total number of clones sequenced & 6,528 \\
Number of high-quality ESTs & 5,542 \\
Average length of high quality ESTs (bp) & 473 \\
Number of contigs & 635 \\
Number of ESTs in contigs & 1,489 \\
Number of singletons & 4,053 \\
Number of unique sequences & 4,688 \\
\hline
\end{tabular}

(17\%); 19 contained 4 ESTs; four contained 5 ESTs, three contained 6 ESTs; and one contained 51 ESTs (Table 2). Clearly, most of the clusters were small, a reflection of high efficiency in normalization and subtraction. The single large cluster was from mitochondrial sequences, and that could have been missed in the subtraction.

The ESTs generated from this study were searched against ESTs of C. virginica in dbEST using BLASTN. Of the 4,688 unique sequences generated in this study, 901 (19.2\%) had significant hits $\left(e \leq 10^{-5}\right)$ with existing ESTs from $C$. virginica, while 3,787 (80.8\%) were found to be novel $C$. virginica ESTs. Therefore, this EST collection represented a significant addition to the existing oyster EST resources.

\section{Putative identities of the ESTs}

In order to make an assessment for the putative identities of the sequenced ESTs, all ESTs were subjected to BLASTX similarity searches. Of the 4,688 unique sequences, 2,174 $(46.4 \%)$ had significant matches $\left(\mathrm{E} \leq 10^{-5}\right)$ to the nonredundant (nr) protein database using BLASTX (Additional file 1). Of the unique sequences with matched homologies in the nr protein database, seven $(0.32 \%)$ had an E-value of $1 \mathrm{e}-100$ or less (Figure 1) and are therefore considered highly significant homology [28]. About $58 \%$ had significant homology (E-values between 1e-20 and 1e-99) and thus, are considered moderately similar $[28,29]$. About $42 \%$ of the ESTs were assigned weak homology (E-values between 1e-05 and 1e-19) and are therefore weakly similar. Among the various organisms that

\section{Table 2: Statistics of BLASTX searches}

\begin{tabular}{lc}
\hline Number of unique sequences & 4,688 \\
Number of unique sequences with BLASTX hits & 2,174 \\
Percentage of unique sequences with BLASTX hits & 46.4 \\
Number of contigs containing & 500 \\
2 ESTs & 108 \\
3 ESTs & 19 \\
4 ESTs & 4 \\
5 ESTs (homologues of actin, tubulin, and two unknown & \\
genes) & 3 \\
6 ESTs (all unknown) & 1 \\
\hline I ESTs (homologous to oyster mitochondrial genome) & 1 \\
\hline
\end{tabular}

have protein sequences in GenBank, the C. virginica ESTs generated from this study had the highest number of BLASTX hits to the purple sea urchin Strongylocentrotus purpuratus $(16 \%)$, followed by zebrafish Danio rerio $(10 \%)$, honey bee Apis melifera (6\%), and chicken Gallus gallus (6\%) (Figure 2). Among the organisms listed in "other" (43\% of total), 13 ESTs $(0.6 \%)$ had significant hits to $C$. virginica proteins in the database and 35 ESTs $(1.6 \%)$ had hits with the Pacific oyster, Crassostrea gigas.

Of the putatively identified genes, 29 different putative proteins were related to stress response, 10 were related to immune response, and 13 were related to defense responses (Table 3 ). These genes are of interest for further studies in relation to disease resistance, and stress responses of oysters, a significant issue in oyster industries.

Of the 2,514 unique sequences without significant matches to the nr protein database, 6 (includes 4 contigs consisting of 57 ESTs and 2 singletons) had matches using the BLASTN algorithm (E-value $\leq \mathrm{e}-5)$. All of these correspond to mtDNA sequences.

\section{Gene ontology annotation}

Gene Ontology (GO) categories were assigned to 1,104 unique ESTs with BLASTX hits using Blast2GO. Figure 3 shows the percentage distributions of gene ontology terms ( $3^{\text {rd }}$ level GO terms) according to the GO consortium. Cellular physiological process $(80 \%)$ was the most dominant $3^{\text {rd }}$ level term out of the 761 unique sequences which were annotated to the Biological Process GO category. This was followed by metabolism at $62 \%$. Only $4 \%$ were assigned to the Biological Process subcategory response to stress. Protein binding (26\%) was the most dominant out of 952 ESTs with significant protein hits which were assigned to Molecular Function category at $3^{\text {rd }}$ level. This

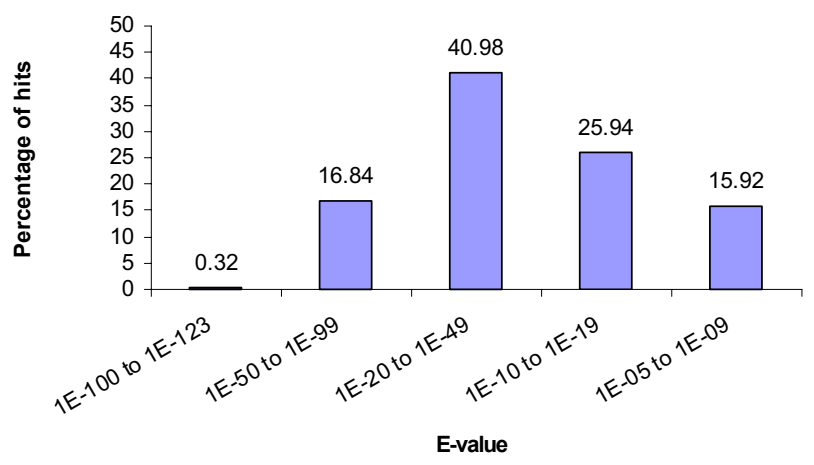

\section{Figure I}

Distribution of E-values from the top hit in the non-redundant protein database. 


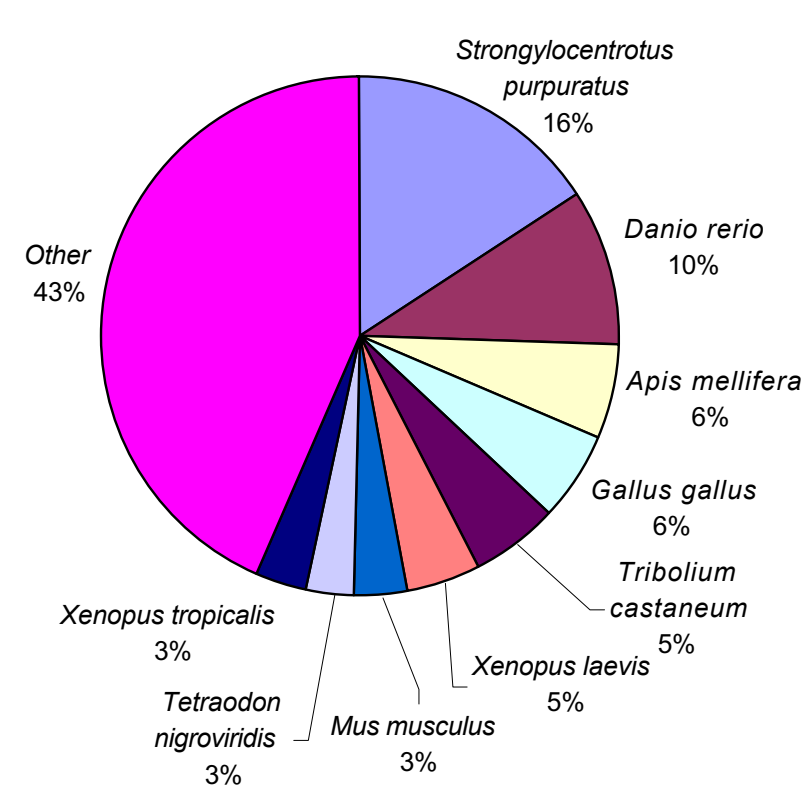

Figure 2

Organisms with the most protein hits. The proportion of putative transcripts with BLASTX matches (E-value $\leq 10^{-5}$ ) in the non-redundant protein database classified according to the organism of the "top hit" protein sequence.

was followed by hydrolase activity and nucleotide binding at $17 \%$ each. GO terms at higher and lower levels for each of the three main GO categories as well as the unique ESTs which fall on each term are given in additional file 2.

\section{Microsatellites-containing ESTs}

Thirty-five (35) microsatellites were found in 32 of the 4,688 unique EST sequences using Msatfinder. The major types of the identified microsatellites were dinucleotide (17) and trinucleotide (16) (Table 4). Of the 32 unique ESTs with microsatellites, 17 have sufficient flanking sequences for the design of 18 primers, and are therefore potentially useful for genetic linkage mapping. Two (2) of the 32 microsatellite-containing ESTs have significant matches to the nr database. These are contig 97 (GenBank accession nos. EH644779 and EH646080) which is homologous to an unnamed protein product in Tetraodon nigroviridis and contig 366 (GenBank accession nos. EH647022 and EH644181) which is homologous to a predicted protein similar to axonemal leucine-rich repeat protein in Strongylocentrotus purpuratus. Of the microsatellites containing ESTs, two contigs were assembled. In silico comparison of the sequences included in the two contigs indicated that the one microsatellite was polymorphic while the other microsatellite was not polymorphic between the two sequenced ESTs.

\section{Single nucleotide polymorphism}

Single nucleotide polymorphism (SNP) has recently become the marker type of choice for linkage and QTL analysis. In most cases, SNP discovery has relied on genomic sequencing, BAC end sequencing, or targeted SNP discovery [30-33]. In the eastern oyster, there have been no reports on large-scale SNP identification. In this study, we took advantage of the existing ESTs with high redundancy along with the ESTs reported here. A total of 1,486 contigs were assembled including 7,702 oyster EST sequences. A total of 6,533 putative SNPs were identified including 2,528 transitions, 1,933 transversions, and 2,072 indels (Table 5). These SNPs represented a rate of 0.59 SNP per 100 base pairs. However, as the quality scores were not available for all ESTs used in the analysis, the putative SNPs could have been caused by sequencing errors as well as the true SNPs. In order to provide some assessment of the SNPs, the putative SNPs were categorized based on the contig sizes. Clearly, the larger the number of sequences involved in a contig, the more likely the SNPs can be checked as to whether the putative SNPs represent sequence errors or real SNPs. As shown in Table $6,2,108(32.3 \%)$ putative SNPs were identified from contigs with only two sequences; 1,856 (28.4\%) putative SNPs were identified from contigs with three sequences; $1,580(24.2 \%)$ putative SNPs were identified from contigs with four sequences; and 989 (15.1\%) putative SNPs were identified from contigs with five or more sequences (Table 6).

\section{Discussion}

This work produced a total of 5,542 ESTs representing 4,688 unique sequences. This EST collection represents the largest number of unique sequences from the eastern oysters. Previous efforts in EST sequencing from this species revealed a high level of sequencing redundancy, largely due to very high proportion of mitochondrial genes $[12,17]$. In this work, the cDNA library was normalized, along with subtraction of the most abundantly expressed genes as determined from previous EST sequencing efforts. Cluster analysis indicated that only one contig was large representing mitochondrial sequences. For the most part, however, the normalized/ subtracted cDNA library allowed efficient generation of unique EST sequences. This suggested that not only normalization, but also subtraction is required for the construction of cDNA libraries suitable for large-scale EST analysis in oysters. Our EST analysis here had a gene discovery rate of $84.6 \%$, or a redundancy rate of $15.4 \%$. Clearly, this is a reflection of the quality of the normalized library. As shown in Figure 4, after sequencing of 6,000 some clones, the rate of gene discovery was still in the linear phase in relation to the number of sequenced clones. This warrants the use of this normalized cDNA library for 
Table 3: C. virginica ESTs similar to genes potentially involved in stress response, defense mechanisms and immune response

\begin{tabular}{|c|c|c|c|c|}
\hline GenBank Accession no. & Putative match & Homolog species & E-value & Hit ID \\
\hline \multicolumn{5}{|l|}{ Stress response } \\
\hline Contigl345 (EH646797 \&EH645944) & $84 \mathrm{kDa}$ heat shock protein & Haliotis tuberculata & 7E-78 & CAK95235.I \\
\hline EH646306 & CCAAT/enhancer binding protein (C/EBP), gamma & Danio rerio & $2 \mathrm{E}-17$ & NP_571961.I \\
\hline EH645I47 & C-type lectin 2 & Anguilla japonica & $5 E-19$ & BAC5402I.I \\
\hline EH 647492 & ecto-ATP diphosphohydrolase I & Homo sapiens & IE-07 & CAB4 1886.1 \\
\hline Contig\। 00 (태644789 \&EH646960) & $\begin{array}{l}\text { ENSANGP000000I7916 (belongs to the ubiquitin-conjugating enzyme } \\
\text { family) }\end{array}$ & Aedes aegypti & $2 \mathrm{E}-65$ & $X P \_310416.4$ \\
\hline EH645340 & Flap endonuclease I-B & Xenopus laevis & $2 \mathrm{E}-72$ & P70054 \\
\hline EH646336 & growth arrest and DNA damage 45 gamma like & Danio rerio & $7 E-10$ & NP_998391.I \\
\hline Contigl310 (태646499 \&EH647053) & Homo sapiens ubiquitin-conjugating enzyme E2N & synthetic construct & $2 \mathrm{E}-69$ & AAP36228.I \\
\hline EH644486 & MGC84195 protein & Xenopus laevis & $8 \mathrm{E}-29$ & AAH82452.I \\
\hline EH646608 & Mn superoxide dismutase & Biomphalaria glabrata & $3 \mathrm{E}-49$ & AAS83980.I \\
\hline EH648076 & novel protein similar to vertebrate methionine sulfoxide reductase $A$ & Danio rerio & $9 \mathrm{E}-35$ & CAH68999.I \\
\hline Contigl5I7 (EH648399 \&EH648432) & Peroxiredoxin $\mathrm{V}$ protein & Branchiostoma belcheri & $4 \mathrm{E}-58$ & AAMI8076.I \\
\hline EH645663 & PREDICTED: EIA binding protein p300 isoform 2 & Pan troglodytes & $6 \mathrm{E}-31$ & XP_00II 68473.1 \\
\hline$\underline{E H} 645265$ and $\underline{E H 646835}$ & PREDICTED: hypothetical protein & Strongylocentrotus purpuratus & $6 \mathrm{E}-37$ & XP_00II89673.I \\
\hline EH646242 & PREDICTED: hypothetical protein isoform 2 & Gallus gallus & IE-07 & $X P \_421849.1$ \\
\hline$\underline{E H} 645065$ & PREDICTED: similar to collectin sub-family member 12 isoform II & Macaca mulatta & $6 \mathrm{E}-10$ & XP_001088438.I \\
\hline EH645286 & PREDICTED: similar to cryptochrome I (photolyase-like) & Tribolium castaneum & IE-39 & XP_972654.I \\
\hline Contigl578 (師648875 \&EH648870) & PREDICTED: similar to DerI-like domain family, member I & Strongylocentrotus purpuratus & $2 \mathrm{E}-70$ & XP_797383.I \\
\hline EH64686I & PREDICTED: similar to dsRNA adenosine deaminase & Strongylocentrotus purpuratus & $3 \mathrm{E}-16$ & XP_00II83590.I \\
\hline EH646254 & $\begin{array}{l}\text { PREDICTED: similar to ER degradation-enhancing alpha-mannosidase- } \\
\text { like }\end{array}$ & Canis familiaris & $6 \mathrm{E}-58$ & XP_533753.2 \\
\hline EH646603 & PREDICTED: similar to GTP-binding-protein CG55I9-PA & Apis mellifera & $6 \mathrm{E}-6 \mathrm{I}$ & XP_392284.2 \\
\hline EH646719 & PREDICTED: similar to mitogen-activated protein kinase kinase 7 & Apis mellifera & IE-56 & XP_396834.I \\
\hline EH648858 & PREDICTED: similar to oxidative stress protein & Strongylocentrotus purpuratus & $\mathrm{IE}-\mathrm{I} 2$ & XP_00II78682.I \\
\hline EH647765 & $\begin{array}{l}\text { PREDICTED: similar to scavenger receptor cysteine-rich protein type } \\
12 \text { precursor }\end{array}$ & Strongylocentrotus purpuratus & $8 \mathrm{E}-19$ & $X P \_791976.2$ \\
\hline EH648904 & PREDICTED: similar to stress-induced-phosphoprotein I & Tribolium castaneum & $5 \mathrm{E}-44$ & XP_967038.I \\
\hline EH646424 & ring finger protein 7 & Gallus gallus & $8 \mathrm{E}-47$ & NP_001026478.I \\
\hline EH645238 & Unknown & Branchiostoma floridae & $3 \mathrm{E}-15$ & AAMI8895.I \\
\hline EH64704I & unnamed protein product & Tetraodon nigroviridis & $2 \mathrm{E}-09$ & CAG05929.1 \\
\hline EH648535 & Zgc: 153458 & Danio rerio & IE-26 & AAI24360.I \\
\hline \multicolumn{5}{|l|}{ Immune response } \\
\hline$\underline{E H 647765}$ & $\begin{array}{l}\text { PREDICTED: similar to scavenger receptor cysteine-rich protein type } \\
12 \text { precursor, partial }\end{array}$ & Strongylocentrotus purpuratus & $8 \mathrm{E}-19$ & XP_791976.2 \\
\hline EH645065 & PREDICTED: similar to collectin sub-family member 12 isoform II & Macaca mulatta & $6 \mathrm{E}-10$ & XP_001088438.I \\
\hline$\underline{E} 6644243$ & peptidoglycan recognition protein & Biomphalaria glabrata & $4 \mathrm{E}-10$ & ABK76644.I \\
\hline EH64686I & PREDICTED: similar to dsRNA adenosine deaminase & Strongylocentrotus purpuratus & $3 \mathrm{E}-16$ & XP_001I83590.I \\
\hline EH645I47 & C-type lectin 2 & Anguilla japonica & $5 \mathrm{E}-19$ & BAC54021.I \\
\hline EH646306 & CCAAT/enhancer binding protein (C/EBP), gamma & Danio rerio & $2 \mathrm{E}-17$ & NP_571961.1 \\
\hline Contigl। 88 (EH645432 \&EH647545) & PREDICTED: leukocyte-derived arginine aminopeptidase isoform 3 & Pan troglodytes & $4 \mathrm{E}-28$ & XP_00II38283.I \\
\hline$\underline{E H} 648526$ & $\begin{array}{l}\text { PREDICTED: inhibitor of kappa light polypeptide gene enhancer in B- } \\
\text { cells, kinase complex-associated protein isoform I }\end{array}$ & Pan troglodytes & $4 \mathrm{E}-34$ & XP_00II42759.I \\
\hline Contigl5I7 (태648399 \&EH648432) & peroxiredoxin $\mathrm{V}$ protein & Branchiostoma belcheri & $4 \mathrm{E}-58$ & AAMI8076.I \\
\hline EH644486 & MGC84I 95 protein & Xenopus laevis & $8 \mathrm{E}-29$ & AAH82452.I \\
\hline \multicolumn{5}{|l|}{ Defense response } \\
\hline EH646306 & CCAAT/enhancer binding protein (C/EBP), gamma & Danio rerio & $2 \mathrm{E}-17$ & NP_57I96I.I \\
\hline EH645I47 & C-type lectin 2 & Anguilla japonica & $5 \mathrm{E}-19$ & BAC54021.I \\
\hline EH645566 & Defensin & Crassostrea gigas & $2 \mathrm{E}-16$ & CAJI9280.I \\
\hline EH645733 & Lysozyme & Crassostrea virginica & $3 \mathrm{E}-72$ & BAE47520.I \\
\hline EH644486 & MGC84195 protein & Xenopus laevis & $8 \mathrm{E}-29$ & AAH82452.I \\
\hline EH644243 & Peptidoglycan recognition protein & Biomphalaria glabrata & $4 \mathrm{E}-10$ & ABK76644.I \\
\hline EH645480 \&EH649320 & Peptidoglycan recognition protein SI precursor & Chlamys farreri & IE-25 & AAY53765.I \\
\hline Contigl5I7 (EH648399 \&EH648432) & Peroxiredoxin $\mathrm{V}$ protein & Branchiostoma belcheri & $4 \mathrm{E}-58$ & AAMI8076.I \\
\hline EH648526 & $\begin{array}{l}\text { PREDICTED: inhibitor of kappa light polypeptide gene enhancer in B- } \\
\text { cells }\end{array}$ & Pan troglodytes & $4 \mathrm{E}-34$ & XP_00II42759.I \\
\hline Contig\/88 (EH645432 \&EH647545) & PREDICTED: leukocyte-derived arginine aminopeptidase isoform 3 & Pan troglodytes & $4 \mathrm{E}-28$ & XP_00II38283.I \\
\hline EH645065 & PREDICTED: similar to collectin sub-family member I 2 isoform II & Macaca mulatta & $6 \mathrm{E}-10$ & XP_001088438.I \\
\hline EH64686I & PREDICTED: similar to dsRNA adenosine deaminase & Strongylocentrotus purpuratus & $3 \mathrm{E}-16$ & XP_00II83590.I \\
\hline$\underline{E H} 647765$ & $\begin{array}{l}\text { PREDICTED: similar to scavenger receptor cysteine-rich protein type } \\
12 \text { precursor }\end{array}$ & Strongylocentrotus purpuratus & $8 \mathrm{E}-19$ & XP_791976.2 \\
\hline
\end{tabular}


(a) Biological Process

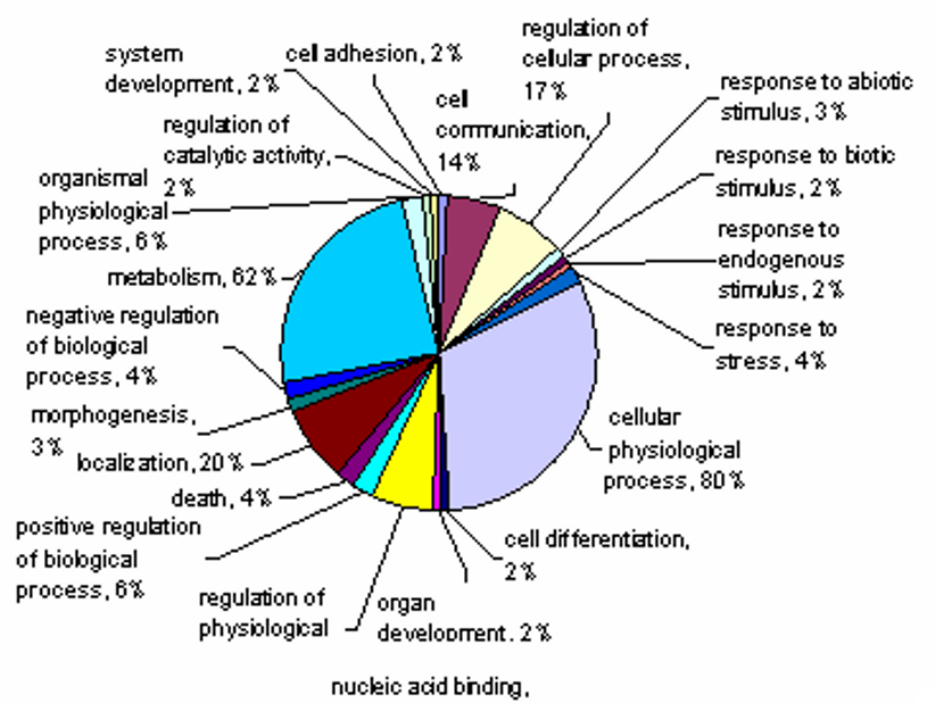

(b) Molecular Function

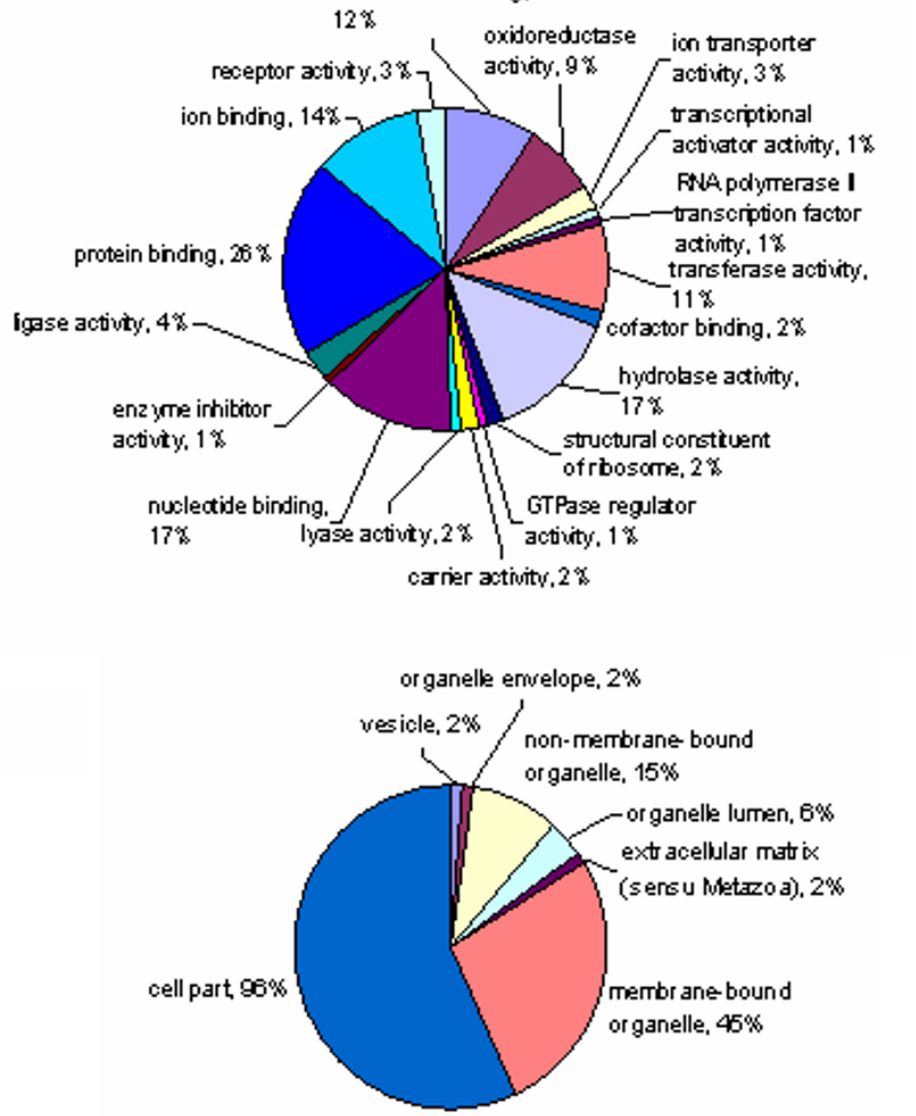

Figure 3

Gene Ontology (GO) assignment (3rd level GO terms) of I, I 04 C. virginica annotated ESTs. The total numbers of ESTs annotated for each main category are 76I for Biological Process, 952 for Molecular Function, and 6I4 for Cellular Component. Since a gene product could be assigned to more than one GO term, the percentages in each main category do not add up to $100 \%$. 
additional EST sequencing when funding situation permits.

Similarity searches of the newly generated ESTs against the existing ESTs in the dbEST revealed that of the 4,688 unique sequences generated in this study, only 901 (19.2\%) had significant hits with existing ESTs from $C$. virginica, while 3,787 (80.8\%) were found to be novel C. virginica ESTs. Therefore, this EST collection represented a significant addition to the existing oyster EST resources. These novel ESTs should provide the material basis for the new editions of the oyster microarrays.

The high percentage of C. virginica ESTs (54\% in this study and in [12]) with no hits in the protein database implies that there is an enormous potential for discovery of new genes in this organism and possibly new gene networks and metabolic pathways [34]. However, we realize that the ESTs were relatively short, and many of the ESTs could still be within the $5^{\prime}$ untranslated region (UTR) such that their identities could not be revealed by sequence similarity comparisons. Efforts should be made in the generation of complete cDNA sequences in this species in order to provide a greater level of assessment of its gene contents and similarities to various other species in the evolutionary spectrum.

A number of stress-, immune-, and defense-related transcripts were putatively identified from this study (e.g., Table 3). These genes are of particular interest to oyster researchers because of relentless environmental pressure on natural and farmed oyster populations brought about by the increasing use of coastal zones and also because of the devastating effects of diseases [11-13]. In this study, $\mathrm{GO}$ annotation of sequences with protein matches in $\mathrm{nr}$ database identified 29 distinct transcripts which are potentially involved in stress responses, 10 distinct transcripts that are potentially involved in immune responses, and 13 distinct transcripts that are potentially involved in defense responses (Table 3). While many of these genes were reported in previous studies on C. virginica ESTs [1113 ], additional studies of these genes are needed to determine their expression in relation to stresses or diseases in order to develop molecular indicators for environmental stresses.

Among the myriad of applications of ESTs is the development of microsatellite and SNP markers. This work allowed the identification of 32 microsatellite-containing ESTs, of which 18 had sufficient flanking sequences for primer design. These microsatellites should be useful for genetic linkage mapping in this species. However, polymorphism needs to be tested in specific resource families. A large number $(6,533)$ of putative SNPs were identified from the overlapping sequences of ESTs. These putative
Table 4: Microsatellite-containing ESTs with available designed primers using Msatfinder

\begin{tabular}{lccc}
\hline $\begin{array}{l}\text { GenBank } \\
\text { Accession no. }\end{array}$ & Length (bp) & Repeat motif & No. of repeats \\
\hline$\underline{E H 644527}$ & 363 & AGG & 7 \\
$\underline{E H 644818}$ & 580 & TC & 17 \\
$\underline{E H 645930}$ & 655 & GTG & 7 \\
$\underline{E H 646768}$ & 629 & CAA & 10 \\
$\underline{E H 647168}$ & 561 & GAG & 6 \\
$\underline{E H 647292}$ & 528 & AAC & 7 \\
$\underline{E H 647319}$ & 477 & ATTG & 6 \\
$\underline{E H 647493}$ & 376 & GA & 14 \\
$\underline{E H 647621}$ & 657 & AAG & 6 \\
$\underline{E H 647703}$ & 423 & AG & 18 \\
$\underline{E H 647704}$ & 643 & TC & 13 \\
$\underline{E H 647722}$ & 634 & AGA & 7 \\
$\underline{E H 647722}$ & 634 & GAA & 14 \\
$\underline{E H 647780}$ & 316 & AAC & 8 \\
$\underline{E H 647816}$ & 434 & TG & 8 \\
$\underline{E H 648299}$ & 616 & AG & 22 \\
$\underline{E H 648644}$ & 534 & CAA & 6 \\
$\underline{E H 649350}$ & 509 & GAA & 8 \\
\hline
\end{tabular}

SNPs are potentially useful for genetic linkage mapping and for the analysis of quantitative traits of the eastern oysters. However, validation and polymorphic analysis must be performed before these putative SNPs can be used. That is because a large proportion of these putative SNPs were identified from contigs with just two or three sequences. In the absence of the quality scores, it was not possible for us to differentiate the true SNPs from sequence errors. In spite of this setback, the putative SNPs identified from this study represent the first large set of SNPs from the eastern oysters. With additional validation, as well as testing in specific resource families for their polymorphism will make them useful markers for genetic analysis in oysters. In a recent study, over $80 \%$ of the SNPs derived from GenBank sequences have been validated as true SNPs in the eastern oyster [35].

\section{Conclusion}

A high-quality normalized/subtracted cDNA library was constructed as determined by the high gene discovery rate (84.6\%) with over 6,000 clones of ESTs being sequenced.

Table 5: Summary of putative SNP identification from oyster EST resources

\begin{tabular}{lc}
\hline Total sequences analysed & 7702 \\
Number of contigs & 1486 \\
Total SNPs detected & 6533 \\
SNP frequency & $0.59 / 100 \mathrm{bP}$ \\
Total number of transitions & 2528 \\
Total number of transversions & 1933 \\
Total number of Indels & 2072
\end{tabular}


Table 6: Putative SNP distribution in contigs with various numbers of ESTs

\begin{tabular}{lcc}
\hline & Number of contigs & Putative SNP sites \\
\hline with $>50$ sequences & 7 & 389 \\
with II-50 sequences & 70 & 171 \\
with $6-10$ sequences & 132 & 253 \\
with 5 sequences & 74 & 176 \\
with 4 sequences & 129 & 1580 \\
with 3 sequences & 262 & 1856 \\
with 2 sequences & 812 & 2108 \\
Total & 1486 & 6533
\end{tabular}

We have generated 5,542 ESTs representing 4,688 unique sequences. Of the 4,688 unique sequences, the majority $(3,787)$ were novel ESTs for this species. Therefore, this EST collection represents a significant addition to the existing EST resources of the eastern oysters. A good fraction $(46 \%)$ of the unique ESTs had significant similarities to known sequences in GenBank. These ESTs should serve as valuable resources for the development of microarrays useful for functional genomic analysis. In addition to the use as EST resources, we have also identified putative microsatellite and SNP markers. Once validated and tested for polymorphism, these microsatellite and SNP markers should be useful for genetic linkage and QTL analysis in oysters.

\section{Methods}

\section{Tissue source and RNA isolation}

Oysters from Rutgers University (NEHY-53) were used in this study. Samples of tissues (50 mg from 4 oysters for each tissue type) were excised from gill, mantle, digestive tract and gonad, and adductor muscle. In addition, about

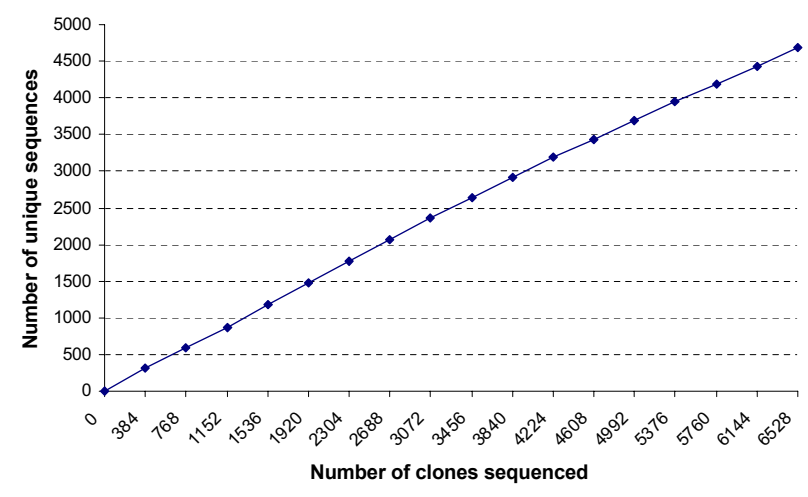

\section{Figure 4}

Low redundancy of $C$. virginica ESTs. Number of unique ESTs were plotted as a function of the total number of clones sequenced. Note that the relationship was nearly linear, suggesting a high rate of gene discovery.
$100 \mathrm{mg}$ of tissue was obtained from one whole juvenile oyster and hemocytes were extracted from 12 oysters. Total RNA was prepared from each sample by using RNeasy Mini kits (Qiagen, Valencia, CA). Total RNA quality and quantity were checked by agarose gel electrophoresis containing formaldehyde and by using a spectrophotometer. Equal amounts of total RNA from each sample listed above were mixed for cDNA library construction.

\section{Construction of normalized and subtracted cDNA library}

The Creator $^{\mathrm{TM}}$ SMART $^{\mathrm{TM}}$ cDNA Library Construction Kit (Clontech, Mountain View, CA) and components from the TRIMMER-DIRECT Kit from Evrogen (Moscow, Russia) were used for the construction of the normalized cDNA library. One microgram $(1 \mu \mathrm{g})$ of mixed total RNA was combined with $1 \mu$ of SMART IV oligonucleotide (Clontech) and $1 \mu$ l CDS-3 $\mathrm{M}$ adapter (Evrogen) for firststrand cDNA synthesis. The reaction was incubated at $72^{\circ} \mathrm{C}$ for $2 \mathrm{~min}$ followed by immediate cooling on ice for $2 \mathrm{~min}$. Then, $2 \mu \mathrm{l}$ of $5 \mathrm{X}$ first strand buffer, $1 \mu \mathrm{l}$ of DTT (20 $\mathrm{mM}), 1 \mu \mathrm{l}$ of dNTP mix ( $10 \mathrm{mM})$, and $1 \mu \mathrm{l}$ of PowerScript reverse transcriptase were added to the tube and incubated at $42^{\circ} \mathrm{C}$ for $1 \mathrm{hr}$ in a thermal cycler (PTC-100, BioRad, Hercules, CA) and placed on ice. The SMART cDNA cloning system allows the enrichment of full-length cDNA through the use of a 5'-linker with 3'-GGG tails. Reverse transcriptase has terminal transferase activity that preferentially adds three additional $\mathrm{Cs}$ at the end of first strand cDNA. As a result, the first strand cDNA is able to base pair with the 5'-linker with 3'-GGG tails. Once base paired, the reverse transcriptase switches templates and extends into the linker sequences allowing PCR amplification of fulllength cDNA using a single primer (the 5'-linker has the same sequences as the linker containing poly-T used for the synthesis of the first strand cDNA). Truncated cDNAs are not able to base pair with the 5 '-linker and, therefore, get lost in the PCR amplification of the full-length cDNA. The first strand cDNA was initially amplified by long-distance PCR (LD-PCR) using hot-start amplification. For the reaction, the following were combined in a reaction tube: $1.5 \mu \mathrm{l}$ of the first strand CDNA, $60 \mu \mathrm{l}$ of sterile deionized water, $7.5 \mu \mathrm{l}$ of $10 \mathrm{X}$ Advantage 2 PCR buffer, $1.5 \mu \mathrm{l}$ of $50 \mathrm{X}$ dNTP mix, $3 \mu$ l of 5' PCR primer and $1.5 \mu$ l of 50X Advantage 2 polymerase mix. The tube was mixed and briefly centrifuged and added to a pre-heated $\left(95^{\circ} \mathrm{C}\right)$ thermal cycler. Cycle settings were $95^{\circ} \mathrm{C}$ for $1 \mathrm{~min}$ followed by 19 cycles of $95^{\circ} \mathrm{C}$ for $7 \mathrm{sec}, 66^{\circ} \mathrm{C}$ for $20 \mathrm{sec}$, and $72^{\circ} \mathrm{C}$ for 5.5 min. The product was analyzed on a $1.1 \%$ agarose gel to determine the sizes and amount of the cDNA products before proceeding to the next step. The LD-PCR reaction was purified and eluted in $30 \mu \mathrm{l}$ of sterile nanopure water using the QIAquick PCR Purification Kit (Qiagen). For the normalization procedure, the TRIMMER-DIRECT Kit from Evrogen (Moscow, Russia) was used. This system is specially developed to normalize cDNA enriched with full 
length sequences. The cDNA from the LD-PCR was quantified $(\sim 200 \mathrm{ng} / \mu \mathrm{l})$ and $1 \mu \mathrm{l}$ was mixed with $1 \mu \mathrm{l}$ of $4 \mathrm{X}$ hybridization buffer, $1 \mu \mathrm{l}$ of sterile water, and $1 \mu \mathrm{l}$ ( $\sim 500$ $\mathrm{ng} / \mu \mathrm{l}$ ) of PCR fragments of 135 abundant ESTs (see additional file 3 for the list) from a previous oyster cDNA library developed in our lab [12]. The mix was overlaid with mineral oil and incubated for $3 \mathrm{~min}$ at $98^{\circ} \mathrm{C}$ then at $70^{\circ} \mathrm{C}$ for $4 \mathrm{hr}$. Then, $5 \mu \mathrm{l}$ of $2 \mathrm{X}$ DSN buffer (preheated to $70^{\circ} \mathrm{C}$ ) and $0.25 \mathrm{Kunitz}$ units of DSN enzyme were added and incubated at $70^{\circ} \mathrm{C}$ for $20 \mathrm{~min}$. The DSN enzyme specifically degrades double-stranded molecules. The reaction was inactivated by adding $10 \mu \mathrm{l}$ of DSN stop solution, and sterile water added to a final volume of 40 $\mu \mathrm{l}$. Following normalization, two rounds of PCR were performed using $1 \mu \mathrm{l}$ of the normalization reaction as template. A shorter primer M1 (first 23 bases of the SMART IV oligonucleotide) was used in the first round of PCR with 15 amplification cycles using the same thermal cycling parameters as above; and an even shorter primer M2 (first 20 bases of the SMART IV oligonucleotide) was used in the second round of PCR for 15 amplification cycles of $95^{\circ} \mathrm{C}$ for $7 \mathrm{sec}, 64^{\circ} \mathrm{C}$ for $20 \mathrm{sec}$, and $72^{\circ} \mathrm{C}$ for $5.5 \mathrm{~min}$. Products were checked on a $1.1 \%$ agarose gel. The PCR products were quantified and $3 \mu \mathrm{g}$ were used for treatment with proteinase K. All the subsequent procedures including proteinase K treatment, restriction digestion with Sfi I, size fractionation, and ligation followed the manufacturer's instructions (Clontech). The cDNA was ligated to the pDNR-LIB vector. Electroporation (MicroPulser, BioRad, Hercules, CA) was performed using DH12S electrocompetent cells following supplier's instructions (Invitrogen). A total of about $8 \times 10^{5}$ primary recombinant clones were obtained, the average insert size was $1650 \mathrm{bp}$, and the library was amplified, titred, and stored in $25 \%$ of glycerol stocks in a $-80^{\circ} \mathrm{C}$ freezer. When needed, clones were plated on Luria-Bertani (LB) agar medium containing $(50 \mu \mathrm{g} / \mathrm{ml}$ chloramphenicol) and grown overnight at $37^{\circ} \mathrm{C}$. Then, colonies were randomly picked, inoculated in 384-well microtitre plate (containing LB medium, 50 $\mu \mathrm{g} / \mathrm{ml}$ chloramphenicol, and $10 \%$ glycerol), incubated overnight with shaking at $37^{\circ} \mathrm{C}$, and stored in a $-80^{\circ} \mathrm{C}$ freezer until further use.

\section{Plasmid isolation and DNA sequencing}

Clones were transferred from 384-well plates to 96-well plates containing LB medium with $50 \mu \mathrm{g} / \mathrm{ml}$ chloramphenicol and grown for about $20 \mathrm{hr}$ prior to plasmid isolation. Plasmid DNA was isolated from 6,528 randomly selected clones using Perfectprep ${ }^{\circledR}$ Plasmid 96 Vac, Direct Bind Kit (Eppendorf). Sequences of cDNAs were sequenced from their 5' end using Big Dye terminator and M13 primer (5'TGTAAAACGACGGCCAGT3') on an ABI $3130 x l$ Genetic Analyzer (Applied Biosystems, Foster City, CA) following manufacturer's protocol.

\section{EST processing, contig assembly and analysis}

The chromatogram files were exported to the PHRED program [36] for basecalling and removal of poor quality sequences. Then, vector sequence, adapter region, and poly(A) tails were trimmed from the sequence using Vector NTI Advance 10 (Invitrogen Corporation, 2005). Trimmed sequences were further screened by including the vector sequence in the contig assembly using the ContigExpress in Vector NTI Advance ${ }^{\mathrm{TM}} 10$ (Invitrogen Corporation, 2005) and discarding all ESTs that formed a contig with the vector. High quality ESTs (at least $100 \mathrm{bp}$ after removal of vector sequence, adapter, and poly(A) tail) were then assembled into clusters of contiguous sequences (contigs). Three software programs were used for contig assembly, namely, PHRAP, CAP3 [37], and Vector NTI Advance ${ }^{\mathrm{TM}}$ 10. After trying the default parameters of the three programs, varying the stringencies of the different parameters, and manually examining the contigs, the results for Vector NTI (using more stringent parameters, i.e, overlap length cutoff of 50 and overlap percent identity of 90) were retained for further analysis. The ContigExpress module in Vector NTI Advance ${ }^{\mathrm{TM}} 10$ also makes use of CAP3 to drive the assembly process (Invitrogen Corporation, 2005). The consensus sequence of each contig and singletons comprised the unique sequences which were compared against the National Center for Biotechnology Information (NCBI) nonredundant protein database using BLASTX. ESTs that did not match sequences in the protein database were further analyzed by searching for similarities at the nucleotide level by using BLASTN. Novel ESTs were also identified by comparison with C. virginica EST sequences in dbEST at NCBI using BLASTN. The E-value cutoff was $1 e-5$.

\section{Gene ontology annotation}

Sequences with BLASTX hits were mapped and annotated according to gene ontology terms (GO) using the program Blast2GO [38]. The distribution of genes in each of the main ontology categories was examined and the percentages of unique sequences in each of the assigned GO terms were computed. In each of the three main categories of GO, namely, biological process, molecular function, and cellular component [39], $100 \%$ was considered as the total number of unique sequences having an assigned GO term. Thus, in each main category, the percentages do not add up to $100 \%$ because some deduced proteins have more than one GO category assigned to them [40].

\section{Bioinformatic mining of microsatellites and SNPs}

The set of 4,688 unique sequences was searched for microsatellites using the web-based software, Msatfinder v. 2.0.9 [41]. The thresholds or minimum repeat number used for the search was 8 for dinucleotide microsatellites, 6 for trinucleotide microsatellites, and 5 for tetra- and pentanucloetide microsatellites. Microsatellite-containing 
ESTs were identified as candidates for marker development if they contained sufficient flanking sequences on either side of the repeats for primer design using Msatfinder. All existing C. virginica ESTs in NCBI's dbEST were added to the ESTs generated in this work for detection of putative SNPs using the AutoSNP program with default parameters [42]. Thus, a total of 14,560 C. virginica ESTs were searched for putative SNPs.

\section{Accession numbers}

The ESTs generated from this study have been deposited in GenBank and were assigned accession numbers from $\underline{\mathrm{EH} 643873}$ to EH649414.

\section{Authors' contributions}

JQ conducted the major part of this study. SW assisted in data analysis and manuscript preparation. PL and EP constructed the normalized and subtracted cDNA library. JA assisted in EST sequencing. YW, LW, YS and XG prepared the oyster tissue samples and extracted the RNA, and revised the manuscript. RW provided oyster samples and participated in biological studies of the project. ZL supervised the entire study and prepared the manuscript. All authors read and approved the final manuscript.

\section{Additional material}

\section{Additional file 1}

C. virginica unique sequences with BLASTX hits in the non-redundant protein database. The table includes EST name, accession number, hit ID, BLAST annotation of the top hit, E-value, organism of the top hit, number of GO annotations, and GO IDs

Click here for file

[http://www.biomedcentral.com/content/supplementary/14712164-8-157-S1.xls]

\section{Additional file 2}

Details of GO annotation. This table provides the detailed information of GO annotation of each contig sequence or EST sequence.

Click here for file

[http://www.biomedcentral.com/content/supplementary/1471-

2164-8-157-S2.xls]

\section{Additional file 3}

Unigene clusters used for subtraction. This table provides the detailed information of the unigene clusters used for the subtraction during normalized cDNA library construction.

Click here for file

[http://www.biomedcentral.com/content/supplementary/14712164-8-157-S3.xls]

\section{Acknowledgements}

This project was supported by a grant from NOAA SeaGrant Gulf Oyster Industry Program awarded to ZL, RW, and XG.

\section{References}

I. Carriker MR, Gaffney PM: A catalogue of selected species of living oysters (Ostreacea) of the world. In The Eastern oyster Crassostrea virginica Edited by: Kennedy VS, Newell RIE, Eble AF. Maryland Sea Grant College, USA; 1996: I- 18.

2. Carlton JT, Mann R: Transfers and world-wide introductions. In The Eastern oyster Crassostrea virginica Edited by: Kennedy VS, Newell RIE, Eble AF. Maryland Sea Grant College, USA; 1996:69I-706.

3. Lenihan $\mathrm{HS}$, Peterson $\mathrm{CH}$ : How habitat degradation through fishery disturbance enhances impacts of hypoxia on oyster reefs. Ecol Appl I998, 8(I): | 28- 140

4. Jackson JB, Kirby MX, Berger WH, Bjorndal KA, Botsford LW, Bourque BJ, Bradbury RH, Cooke R, Erlandson J, Estes JA, et al.: Historical overfishing and the recent collapse of coastal ecosystems. Science 200I, 293(5530):629-637.

5. Nelson KA, Leonard LA, Posey MH, Alphin TD, Mallin MA: Using transplanted oyster (Crassostrea virginica) beds to improve water quality in small tidal creeks: a pilot study. J Exp Mar Biol Ecol 2004, 298(2):347-368.

6. Lannig G, Flores JF, Sokolova IM: Temperature-dependent stress response in oysters, Crassostrea virginica : pollution reduces temperature tolerance in oysters. Aquat Toxicol 2006, 79(3):278-287.

7. Fisher WS, Oliver LM, Winstead JT, Long ER: A survey of oysters Crassostrea virginica from Tampa Bay, Florida: associations of internal defense measurements with contaminant burdens. Aquat Toxicol 2000, 5 I ( I): I I 5-138.

8. Oliver LM, Fisher WS, Winstead JT, Hemmer BL, Long ER: Relationships between tissue contaminants and defense-related characteristics of oysters (Crassostrea virginica) from five Florida bays. Aquat Toxicol 200I, 55(3-4):203-222.

9. $\mathrm{Yu} Z$, Guo $\mathrm{X}$ : Genetic linkage map of the eastern oyster Crassostrea virginica Gmelin. Biol Bull 2003, 204(3):327-338.

10. Cunningham C, Hikima J, Jenny MJ, Chapman RW, Fang GC, Saski C, Lundqvist ML, Wing RA, Cupit PM, Gross PS, et al.: New resources for marine genomics: bacterial artificial chromosome libraries for the Eastern and Pacific oysters (Crassostrea virginica and C. gigas). Mar Biotechnol (NY) 2006, 8(5):521-533.

II. Jenny MJ, Ringwood AH, Lacy ER, Lewitus AJ, Kempton JW, Gross PS, Warr GW, Chapman RW: Potential indicators of stress response identified by expressed sequence tag analysis of hemocytes and embryos from the American oyster, Crassostrea virginica . Mar Biotechnol (NY) 2002, 4(I):8I-93.

12. Peatman EJ, Wei X, Feng J, Liu L, Kukuktas H, Li P, He C, Rouse D, Wallace R, Dunham $R$, et al: Development of expressed sequence tags from eastern oyster (Crassostrea virginica): lessons learned from previous efforts. Mar Biotechnol (NY) 2004, 6:S49I-S496.

13. Tanguy A, Guo $X$, Ford SE: Discovery of genes expressed in response to Perkinsus marinus challenge in Eastern (Crassostrea virginica) and Pacific (C. gigas) oysters. Gene 2004, 338(I):|2|-|3|.

14. Jenny MJ, Chapman RW, Mancia A, Chen Y, XMcKillen DJ, Trent H, Lang P, Escoubas J-M, Bachere E, Boulo V, et al.: Characterization of a cDNA microarray for Crassostrea virginica and $C$. gigas. Mar Biotechnol (NY) 2007 in press.

15. He C, Chen L, Simmons M, Li P, Kim S, Liu Z): Putative SNP discovery in interspecific hybrids of catfish by comparative EST analysis. Anim Genet 2003, 34(6):445-448.

16. Serapion J, Kucuktas H, Feng J, Liu Z: Bioinformatic mining of type I microsatellites from expressed sequence tags of channel catfish (Ictalurus punctatus). Mar Biotechnol (NY) 2004, 6(4):364-377.

17. Shimizu N, Lee J-Y, Shimizu Y, Ohtake H, Sato Y, Asakawa S: Genomics of the Pacific oyster Crassostrea gigas . In Aquatic Genomics, Steps Toward a Great Future Edited by: Shimizu N, Aoki T, Hirono I, Takashima F. Tokyo: Springer; 2003:128-132.

18. Durand JP, Goudard F, Pieri J, Escoubas JM, Schreiber N, Cadoret JP: Crassostrea gigas ferritin: cDNA sequence analysis for two heavy chain type subunits and protein purification. Gene 2004, 338(2): 187-195.

19. Gueguen Y, Cadoret JP, Flament D, Barreau-Roumiguiere C, Girardot AL, Garnier J, Hoareau A, Bachere E, Escoubas JM: Immune gene discovery by expressed sequence tags generated from hemocytes of the bacteria-challenged oyster, Crassostrea gigas. Gene 2003, 303:139-145. 
20. Brown BL, Franklin DE, Gaffney PM, Hong M, Dendanto D, Kornfield I: Characterization of microsatellite loci in the eastern oyster, Crassostrea virginica . Mol Ecol 2000, 9(I 2):2217-2219.

21. Reece KS, Ribeiro WL, Gaffney PM, Carnegie RB, Allen SK Jr: Microsatellite marker development and analysis in the eastern oyster (Crassostrea virginica): confirmation of null alleles and non-Mendelian segregation ratios. J Hered 2004, 95(4):346-352.

22. Carlsson J, Reece KS: Eight PCR primers to amplify EST-linked microsatellites in the Eastern oyster, Crassostrea virginica genome. Mol Ecol Notes 2007, 7:257-259.

23. Wang Y, Guo X: Development and characterization of ESTSSR markers in the eastern oyster Crassostrea virginica. J Shellfish Res 2006, 25(2):790.

24. Carlsson J, Morrison CL, Reece KS: Wild and aquaculture populations of the Eastern oyster compared using microsatellites. J Hered 2006, 97(6):595-598.

25. Hedgecock D, Li G, Hubert S, Bucklin K, Ribes V: Widespread null alleles and poor cross-species amplification of microsatellite DNA loci cloned from the pacific oyster, Crassostrea gigas . J Shellfish Res 2004, 23(2):379-385.

26. Li G, Hubert S, Bucklin K, Ribes V, Hedgecock D: Characterization of 79 microsatellite DNA markers in the Pacific oyster Crassostrea gigas. Mol Ecol Notes 2003, 3(2):228-232.

27. $\mathrm{Yu} Z$, Guo X: Identification and mapping of disease-resistance QTLs in the eastern oyster,Crassostrea virginica Gmelin. Aquaculture 2006, 254(I-4): I60-170.

28. Habermann B, Bebin AG, Herklotz S, Volkmer M, Eckelt K, Pehlke K, Epperlein HH, Schackert HK, Wiebe G, Tanaka EM: An Ambystoma mexicanum EST sequencing project: analysis of 17,352 expressed sequence tags from embryonic and regenerating blastema cDNA libraries. Genome Biol 2004, 5(9):R67.

29. Coblentz FE, Towle DW, Shafer TH: Expressed sequence tags from normalized cDNA libraries prepared from gill and hypodermal tissues of the blue crab, Callinectes sapidus . Comp Biochem Physiol Part D Genomics Proteomics 2006, I(2):200-208.

30. Beldade P, Rudd S, Gruber JD, Long AD: A wing expressed sequence tag resource for Bicyclus anynana butterflies, an evo-devo model. BMC Genomics 2006, 7:130.

31. Guryev V, Berezikov E, Cuppen E: CASCAD: a database of annotated candidate single nucleotide polymorphisms associated with expressed sequences. BMC Genomics 2005, 6(I): 10

32. Ryynanen HJ, Primmer CR: Single nucleotide polymorphism (SNP) discovery in duplicated genomes: intron-primed exon-crossing (IPEC) as a strategy for avoiding amplification of duplicated loci in Atlantic salmon (Salmo salar) and other salmonid fishes. BMC Genomics 2006, 7:192.

33. Smits BM, Guryev V, Zeegers D, Wedekind D, Hedrich HJ, Cuppen $\mathrm{E}$ : Efficient single nucleotide polymorphism discovery in laboratory rat strains using wild rat-derived SNP candidates. BMC Genomics 2005, 6: I70.

34. Saavedra C, Bachere E: Bivalve genomics. Aquaculture 2006 , 256(I-4): I- 14.

35. Lee JH, Guo X: Mining EST database for single-nucleotide polymorphisms in the eastern oyster (Crassostrea virginica). Shellfish Res 2006, 25(2):748-749.

36. Ewing B, Hillier L, Wend I MC, Green P: Base-calling of automated sequencer traces using phred. I. Accuracy assessment. Genome Res 1998, 8(3): I75-185.

37. Huang $X$, Madan A: CAP3: A DNA sequence assembly program. Genome Res 1999, 9(9):868-877.

38. Conesa A, Gotz S, Garcia-Gomez JM, Terol J, Talon M, Robles M Blast2GO: a universal tool for annotation, visualization and analysis in functional genomics research. Bioinformatics 2005, 21(18):3674-3676.

39. Ashburner M, Ball CA, Blake JA, Botstein D, Butler H, Cherry JM, Davis AP, Dolinski K, Dwight SS, Eppig JT, et al.: Gene ontology: tool for the unification of biology. The Gene Ontology Consortium. Nat Genet 2000, 25(I):25-29.

40. Vizcaino JA, Gonzalez FJ, Suarez MB, Redondo J, Heinrich J, DelgadoJarana J, Hermosa R, Gutierrez S, Monte E, Llobell A, et al.: Generation, annotation and analysis of ESTs from Trichoderma harzianum CECT 24I3. BMC Genomics 2006, 7:193.

4I. Thurston MI, Field D: Msatfinder: detection and characterisation of microsatellites. CEH Oxford, Mansfield Road, Oxford OXI 3SR 2006 [http://www.genomics.ceh.ac.uk/msatfinder/]
42. Barker G, Batley J, H OS, Edwards KJ, Edwards D: Redundancy based detection of sequence polymorphisms in expressed sequence tag data using autoSNP. Bioinformatics 2003, I 9(3):421-422.
Publish with Biomed Central and every scientist can read your work free of charge

"BioMed Central will be the most significant development for disseminating the results of biomedical research in our lifetime. "

Sir Paul Nurse, Cancer Research UK

Your research papers will be:

- available free of charge to the entire biomedical community

- peer reviewed and published immediately upon acceptance

- cited in PubMed and archived on PubMed Central

- yours - you keep the copyright
BioMedcentral 